\title{
Природа ловушек в флеш памяти на основе high-k диэлектриков \\ Гриценко В.А.
}

ИФП СО РАН, 630090, Новосибирск, пр. Ак. Лаврентьева, 13

DOI 10.34077/Semicond2019-425

Энергонезависимая флеш память сохраняет информацию в течении 10 лет при $85{ }^{\circ} \mathrm{C}$ и широко используется в системах хранения информации, наряду, с жесткими дисками, и в портативных переносных устройствах: мобильные телефоны, фотовидеокамеры, планшеты, ноутбуки, биометрические паспорта, банковские карты и др.

В течении двух десятилетий доминировала флеш память с плавающим затвором, на смену которой пришла $\mathrm{TaN}-\mathrm{Al}_{2} \mathrm{O}_{3}-\mathrm{Si}_{3} \mathrm{~N}_{4}-\mathrm{SiO}_{2}-\mathrm{Si}$, TANOS память на основе локализации электронов и дырок на ловушках в нитриде кремния. Несмотря на то, что память на нитриде кремния была открыта в 1967 году, природа ловушек, ответственных за локализацию электронов и дырок в $\mathrm{Si}_{3} \mathrm{~N}_{4}$, окончательно, была установлена только в 2016 году [1]. В качестве ловушек в $\mathrm{Si}_{3} \mathrm{~N}_{4}$ выступают кремнийкремниевые $\mathrm{Si}-\mathrm{Si}$ связи, или кремниевые нанокластеры. $\mathrm{Si}-\mathrm{Si}$ связи являются амфотерными ловушками, ответственны за локализацию электронов и дырок. Ионизация ловушек в $\mathrm{Si}_{3} \mathrm{~N}_{4}$ осуществляется многофононным механизмом. Термическая и оптическая энергии ловушек в $\mathrm{Si}_{3} \mathrm{~N}_{4}$ лежат в диапазоне $W_{\mathrm{t}}=1.5 \pm 0.1 \mathrm{eV}, W_{\mathrm{opt}}=3.0 \pm 0.1 \mathrm{eV}$. В качестве блокирующего слоя в TANOS используется оксид алюминия, $\mathrm{Al}_{2} \mathrm{O}_{3}$. Термическая и оптическая энергииловушки, ответственных за проводимость $\mathrm{Al}_{2} \mathrm{O}_{3}$ равны $W_{\mathrm{t}}=1.5 \mathrm{eV}, W_{\text {opt }}=3.0 \mathrm{eV}$ соответственно [2].

В настоящее время интенсивно изучается и разрабатывается резистивная память (Resistive Random Access Memory, ReRAM) на основе нестехиометрических диэлектриков $\mathrm{SiO}_{\mathrm{x}}, \mathrm{SiN}_{\mathrm{x}}, \mathrm{TaO}_{\mathrm{x}}$, $\mathrm{HfO}_{\mathrm{x}}, \mathrm{TiO}_{\mathrm{x}}, \mathrm{ZrO}_{\mathrm{x}}, \mathrm{AlO}_{\mathrm{x}}$ [3]. В качестве ловушек в этих материалах, за исключением $\mathrm{SiN}_{\mathrm{x}}$ выступают вакансии кислорода. Энергии ловушек составляют в $\mathrm{SiO}_{\mathrm{x}} W_{\mathrm{t}}=1.5 \mathrm{eV}, W_{\mathrm{opt}}=3.0 \mathrm{eV}$ [4], $\mathrm{TaO}_{\mathrm{x}} W_{\mathrm{t}}=0.85 \mathrm{eV}$,

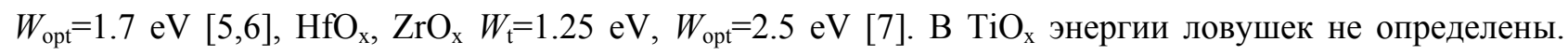
Перенос заряда в $\mathrm{TaO}_{\mathrm{x}}, \mathrm{HfO}_{\mathrm{x}}, \mathrm{ZrO}_{\mathrm{x}}$ лимитируется фонон-облегченным туннелированием между ловушками [8].

В 2011г обнаружен эффект сегнетоэлектрической памяти в тонких пленках нецентросимметричной фазы оксида гафния $\mathrm{HfO}_{2}$. Это привело к разработкам сегнетоэлектрической памяти на оксидах гафния. Мы изучали природу ловушек, ответственных за проводимость сегнетоэлектрической фазы $\mathrm{Hf}_{0.5} \mathrm{Zr}_{0.5} \mathrm{O}_{2}$. в качестве ловушек в этом материале выступаем вакансия кислорода, ловушка имеет следующие параметры: $W_{\mathrm{t}}=1.25 \mathrm{eV}, W_{\mathrm{opt}}=2.5 \mathrm{eV}[8,9]$.

[1] V.A. Gritsenko, N.V. Perevalov, O.M. Orlov, G. Ya. Krasnikov, Appl. Phys. Lett. 109, 06294, (2016).

[2] N. Novikov, V.A. Gritsenko, K.A. Nasyrov, Appl. Phys. Lett. 94, 222904 (2009).

[3] В.А. Гриценко, Д.Р. Исламов, Физика Диэлектрических Пленок: Механизмы Транспорта Заряда и Физические Основы Приборов Памяти, Параллель, Новосибирск (2017).

[4] Damir R. Islamov, Vladimir A. Gritsenko, Timofey V. Perevalov, et. al. Appl. Phys. Lett. 109, 052901 (2016).

[5] Perevalov, Timofey; Gritsenko, Vladimir; Gismatulin, Andrey et. al. Nanotechnology, 29, 264001 (2018).

[6] Vladimir A. Gritsenko, Timofey V. Perevalov, Vitaliy A. Voronkovskii, et.al. ACS Appl. Mater. Interfaces, 10, 3769 (2018).

[7] Vladimir A. Gritsenko, Timofey V. Perevalov, Damir R. Islamov, Physics Reports, 613, 1 (2016).

[8] К.А. Насыров, В.А. Грищенко, УФН, 183, 1099 (2013).

[9] Damir R. Islamov, Vladimir A. Gritsenko, Timofey V. Perevalov, Acta Materialia, 166, 47 (2019).

[10] Д. Р. Исламов, А. Г. Черникова, М. Г. Козодаев, Письма в ЖЭТФ, 102, 610 (2015). 